\title{
Alzheimer's Disease Mortality according to Socioeconomic Factors: Country Study
}

\author{
Peter Tóth (iD), ${ }^{1}$ Beáta Gavurová, ${ }^{1}$ and Miroslav Barták ${ }^{2}$ \\ ${ }^{1}$ Research and Innovation Centre Bioinformatics, TECHNICOM, Košice, Faculty of Economics, Technical University of Košice, \\ Němcovej 32, 04001 Košice, Slovakia \\ ${ }^{2}$ Department of Addictology, First Faculty of Medicine, Charles University and General University Hospital in Prague, Apolinářská 4 , \\ 12800 Praha 2, Czech Republic
}

Correspondence should be addressed to Peter Tóth; peter.toth@tuke.sk

Received 3 October 2018; Revised 12 November 2018; Accepted 27 November 2018; Published 12 December 2018

Academic Editor: Francesco Panza

Copyright ( $\odot 2018$ Peter Tóth et al. This is an open access article distributed under the Creative Commons Attribution License, which permits unrestricted use, distribution, and reproduction in any medium, provided the original work is properly cited.

Aim of the paper is to quantify effects of socioeconomic factors on Alzheimer's Disease Mortality in the Slovak Republic. We applied potential gains in life expectancy (PGLE) method to measure the impact of elimination of Alzheimer's disease on life expectance in Slovak regions. PGLE is based on life table adjustment according to elimination of mortality caused by specific diagnosis. Our dataset consists of all deceased from Slovak Republic from 2001 to 2015. We analyse the impact of unemployment rate, GDP per capita, average wage, and education on life expectance in Slovak regions. To estimate that impact, ordinary least squares (OLS) is applied. According to our model, gross domestic product, average wage, and education influence mortality caused by Alzheimer's disease.

\section{Introduction}

Alzheimer's disease $(\mathrm{AD})$ is degenerative brain disease and the most common cause of dementia. Dementia is a syndrome-a group of symptoms-which has several causes. $\mathrm{AD}$ is in the researches generally defined based on International Classification of Diseases and/or Statistical Manual of Mental Disorders (e.g., Prince et al. [1]). The discussion about how to measure AD is however much more complex as suggested, e.g., Alzheimer Europe discussion paper on ethical issues linked to the changing definitions/use of terms related to $\mathrm{AD}$ [2]. Characteristic signs of dementia are memory, language, problem solving, and other cognitive skills that affect a person's ability to perform day-to-day activities. Much of the AD increase will take in not very faraway future in lowand middle-income countries [3]. Furthermore, AD is an increasing issue in Central and Eastern European countries, including the Slovak Republic.

Qiu, Bäckman, and Winblad [4] estimated that 44 million people are living with dementia throughout the world and about $70 \%$ is caused by $\mathrm{AD}$. $\mathrm{AD}$ has become global challenge and has large impact on both health and social systems (ibid). In 2015, dementia affected some 10.5 million citizens aged between 30 and 95+ years in Europe. This number is estimated to increase to 13.42 million people by 2030 . According to Castro et al. [5], AD entails both direct and indirect economics cost. They suggest that indirect costs are more important in the early and community living $\mathrm{AD}$ patients and that direct costs are increasing with the disease progress.

Based on recent study of Reed et al. [6], total societal costs of caring for patients with $\mathrm{AD}$ vary across countries or regions of Europe with different health care systems. In their study, the mean 18-month societal costs per patient were in France $€ 33,339$, in Germany $€ 38,197$, and in the UK $€ 37,899$ ( $£ 32,501)$. According to Reed et al. [6], the caregiver time spent on basic and instrumental activities of daily living (ADL) contributed the most to societal costs (54\% France, 64\% Germany, and 65\% UK). In 2016, Winblad et al. [7] found in their study of Spain, Sweden, the UK, and the USA that the costs are about EUR 14,500 annually in patients at home setting with higher level of autonomy but for residential care the cost may be higher than EUR 72,500. They also mention the geographical variations of $\mathrm{AD}$ as an important issue. Total 
estimated costs of dementia in 2015 were USD 818 billion. By 2018, dementia will become trillion-dollar disease, rising to USD 2 trillion by 2030 .

According to the European Dementia Monitor 2017 [8], Finland, the UK (England), and the Netherlands were the countries which belong to the most dementia friendly policies in place. The countries were ranked using the categories of care availability, care affordability, treatment, clinical trials, research collaboration, dementia as a priority, dementiafriendliness, legal rights, international conventions, and last but not least care and employment rights. The Slovakia Republic placed at 19th and the Czech Republic 20th place out of 36 European countries. Based on the results, the study reports better outcomes in Central and Eastern Europe than in the Southern Europe. Based on data from this report, Slovakia Republic excelled in care and employment rights in comparison with other European counties (2nd place). The report also suggests that there are no fully funded care services in the Slovakia-the half of services require the copayments and the second half is self-funded. The availability of residential care and the day care are considered to be insufficient; however home care is considered to be sufficient. According to same source, Slovakia is ranking as the 11th country out of 36 European countries in participation in European dementia research collaborations and funding of pan-European dementia research initiatives.

Numerous studies, which are introduced below, address the impact of socioeconomic and genetic factors on Alzheimer's disease. Nicolia, Lucarelli, and Fuso [9] expanded these factors by the impact of various environmental factors (nutrients, pollutants, chemicals, physical activity, and lifestyle, physical and mental stress) to epigenetic markers. Moceri et al. [10] analysed the Alzheimer's disease risk associated with the father's occupation, the age of the parents, the size of the household, the number of siblings, and the birth. Kalaria et al. [11] selected as risk factors for dementia in the developing countries of Asia, Latin America, and Africa age (especially those over 65) and gender (women are more likely to develop dementia than men). Other risk factors include genetic and environmental factors (including early brain development, body growth, socioeconomic conditions, etc.), illiteracy, and educational levels. Ertekin et al. [12] present in their research study of the impact of risk factors on the prevalence of Alzheimer's disease in the Eastern Region of Turkey. The authors examined the relationship between the prevalence of Alzheimer's disease, socioeconomic characteristics, and comorbidities. The incidence of Alzheimer's disease in older age increases in both sexes but increases significantly in women. A statistically significant relationship was also found between the level of education and Alzheimer's disease. With the increasing level of education, the likelihood of Alzheimer's disease is decreasing. The occurrence of Alzheimer's disease was greater in widowed individuals than in married couples. The incidence of Alzheimer's disease was higher for manual workers than for others. Karp et al. [13] in their study examined whether the association between low levels of education and increased risk of Alzheimer's disease and dementia may be explained by the socioeconomic status based on the occupation. The results of their study show that low levels of education and low socioeconomic status expressions of low employment are individually linked to increased risk of Alzheimer's disease and dementia. Evans et al. [14] aimed at assessing the relationship between the three socioeconomic status indicators: education, occupational prestige, and income at risk of clinically diagnosed Alzheimer's disease. The results of their analyses show that socioeconomic status markers (education, prestige, and income) predicted the development of Alzheimer's disease (ranked among risk factors). In individual analyses, less years of formal school attendance, lower incomes, and lower job prestige indicated higher risk of Alzheimer's disease incidence. Wang et al. [15] compared the effects of cardiovascular, cancer, HIV, Alzheimer's disease, and kidney disease on the development of life expectancy by age, race, and gender. Alzheimer's and kidney disease are the only two diseases that have these days a growing mortality trend. From the study results, the degree of impact of each of the disease categories studied on the expected life span of the US population is determined by age, race, and gender.

The goal of the paper is the analysis of available data about mortality caused by Alzheimer's disease in Slovakia in order to quantify effects of socioeconomic indicators in life expectancy in Slovakia regions. The article fills the gap in knowledge, as similar analysis has not yet been performed in the Slovak environment; however there is growing evidence on the importance of analysed factors on AD related mortality in other countries.

\section{Data and Methodology}

2.1. Data. To reach the aim of the paper, we use three datasets. The first dataset is mortality in Slovak Republic provided by the National Health Information Centre (Národné Centrum Zdravotníckych Informácií) of the Slovak Republic. The second database is population data from the Statistical Office of the Slovak Republic (Štatistický úrad Slovenskej Republiky). The third source of our data is Eurostat, from which we use socioeconomic data.

Because of the data availability, we analyse time period from 2001 to 2015. Our mortality database consists of all deceased in Slovak Republic during analysed time period. In this paper, we study effects of socioeconomic indicators on the potential gain in life expectancy when deaths caused by Alzheimer's disease are eliminated. We select four socioeconomic indicators: Gross Domestic Product (GDP) per capita, average nominal monthly wage, unemployment rate, and education level. Education level in region is measured by the percentage of employees with tertiary education. It is assumed that this indicator is more appropriate than number of graduated in region because universities are distributed unevenly among Slovak regions and many students study and live in different regions as well as many of them study abroad. All these indicators measure the level of the region development. According to previous studies, education is factor that reduces risk of Alzheimer's disease.

There are other factors which can potentially affect the number of deaths caused by the AD. The health policy in the 
Slovak Republic is centralized; therefore we do not consider the impact of the health policy in the analysis of regional disparities. The study of the impact of the healthcare facilities is not relevant in case of the regional analysis, because of the fact that the Slovak Republic is small country; there are usually only several specialized healthcare facilities with nationwide scope.

2.2. Methodology. Methodology consists of several steps. The first step is to calculate abridged life tables for all causes of death and abridged life tables eliminating Alzheimer's disease. Then potential gain in life expectancy (PGLE) can be calculated. The last step is panel models estimation in order to quantify impact of selected socioeconomic factors on the PGLE.

Abridged life tables are computed for 5-year age groups except first age group, which is divided into age 0 and ages 1-4. Then, abridged life tables for Slovak regions consist of ages $x \in 0,1,5,10, \ldots, 90,95$. Let ${ }_{n} q_{x}$ be group probability of death for age $x$ with length of the age group $n$, computed by (1), where ${ }_{n} m_{x}$ is observed death rate expressed as ${ }_{n} m_{x}=$ ${ }_{n} D_{x} /{ }_{n} K_{x}$, where ${ }_{n} D_{x}$ is number of deaths and ${ }_{n} K_{x}$ is midyear population size, and ${ }_{n} a_{x}$ denotes distribution of deaths. Typically, it is assumed that deaths are randomly distributed across the age interval; therefore ${ }_{n} a_{x}=2.5$ [13].

$$
{ }_{n} q_{x}=\frac{n \cdot{ }_{n} m_{x}}{1+{ }_{n} m_{x}\left(n-{ }_{n} a_{x}\right)}
$$

Abridged life tables contain age $(x$ to $x+n)$, probability of death $\left({ }_{n} q_{x}\right)$, number of surviving $\left(l_{x}\right)$, proportion of deaths in age group $\left({ }_{n} d_{x}\right)$, person-years lived $\left({ }_{n} L_{x}\right)$, person-years of remaining life in the cohort $\left(T_{x}\right)$, and life expectancy $\left(e_{x}\right)$ [14]. Number of surviving denotes the number of persons from the original population of 100,000 live births who survive to the beginning of each age interval and is computed by (2), for $l_{0}=100,000[14,15]$.

$$
\begin{aligned}
& l_{x+n}=l_{x} \cdot\left(1-{ }_{n} q_{x}\right) \\
& { }_{n} d_{x}=l_{x}-l_{x+n}
\end{aligned}
$$

Person-years lived explains the total time in years lived between two indicated birthdays and is expressed by the following equation:

$$
{ }_{n} L_{x}=\frac{\left(l_{x}+l_{x+n}\right)}{2}
$$

Then, person-years of remaining life $\left(T_{x}\right)$ can be calculated by the following equation:

$$
T_{x}=L_{x}+L_{x+1}+\ldots+L_{95}
$$

Life expectancy explains the expectation of life at a given age and is given by the following equation:

$$
e_{x}=\frac{T_{x}}{l_{x}}
$$

It is necessary to calculate abridged life tables eliminating Alzheimer disease in order to quantify PGLE. Probability of death for age $\mathrm{x}$ with length of age group $\mathrm{n}$ eliminating cause of death $\mathrm{i}\left({ }_{n} q_{x-I}\right)$ is calculated by the following equation [16].

$$
{ }_{n} q_{x}^{-i}=1-{ }_{n} p_{x}^{\left({ }_{n} D_{x}-{ }_{n} D_{x}^{i}\right) /{ }_{n} D_{x}}
$$

Number of surviving $\left(l_{x-i}\right)$, proportion of deaths $\left({ }_{n} d_{x-i}\right)$, person-years lived $\left({ }_{n} \mathrm{~L}_{\mathrm{x}-\mathrm{i}}\right)$, person-years of remaining life in the cohort $\left(\mathrm{T}_{\mathrm{x}-\mathrm{i}}\right)$, and life expectancy $\left(\mathrm{e}_{\mathrm{x}-\mathrm{i}}\right)$ were calculated using formulas (2), (3), (4), (5), and (6), respectively. Only one expectation is age $x=95$, when person-years lived $\left({ }_{n} \mathrm{~L}_{95-\mathrm{i}}\right)$ is given by (8) and person-years of remaining life in the cohort $\left(\mathrm{T}_{95-\mathrm{i}}\right)$ is given by $(9)$ and $(10)$.

$$
\begin{aligned}
{ }_{n} L_{95}^{-i} & =l_{95}^{-i}+l_{95}^{-i} \cdot \frac{q_{95}^{-i}}{2} \\
{ }_{n} T_{95}^{-i} & =\alpha \cdot{ }_{n} L_{95}^{-i} \\
\alpha & =\frac{e_{95} \cdot{ }_{n} l_{95}}{{ }_{n} L_{95}}
\end{aligned}
$$

Potential gain in life expectancy is derived as difference between life expectancy eliminating cause $i$ and life expectancy for all causes. Mathematically potential gain in life expectancy PGLE is explained by the following equation:

$$
P G L E^{-i}=e_{x}^{-i}-e_{x}
$$

To analyse impact of socioeconomic factors on PGLE eliminating Alzheimer's disease, panel data analysis was applied. General linear panel model is defined by (12), where $y_{i t}$ is a dependent variable, $\alpha_{\text {it }}$ and $\beta_{\text {it }}$ are regression coefficients, and $\mathrm{u}_{\mathrm{it}}$ denotes a random disturbance term of mean 0 . Index $\mathrm{i}=$ $1, \ldots, \mathrm{n}$ marks individual index, in our case regions in Slovak Republic and $t=1, \ldots$, T represents time index [17].

$$
y_{i t}=\alpha_{i t}+\beta_{i t}^{T} \mathbf{x}_{i t}+u_{i t}
$$

Parameter homogeneity is often assumed that means $\alpha_{\text {it }}=$ $\alpha$ for all $\mathrm{i}, \mathrm{t}$ and $\beta_{\mathrm{it}}=\beta$ for all $\mathrm{i}, \mathrm{t}$. This is standard linear model, so-called pooling model. If individual component in the general model is correlated with regressors $\mathrm{x}_{\mathrm{it}}$, then $\alpha_{\text {it }}=\alpha_{\mathrm{i}}$ and it is called fixed effects model. If it is not, model is called random effects model. Therefore, we estimate three models: fixed effects model, random effects model, and pooling model. There are many tests how to identify which model is most appropriate. The suitability of the pooling model can be tested using Test of poolability. To decide between fixed effects model and random effects model, Hausman Test is commonly used which compares two sets of estimates [18]. Lagrange multiplier test of individual and time effects introduced by [18] is used to decide which effects are involved in database. Existence of serial correlation is tested by Breusch-Godfrey test [19]. In addition to serial correlation, cross-sectional dependence is tested using Pesaran CD test for cross-sectional dependence in panels [20].

Analysis and all outputs were realized in the R software environment [21]. 


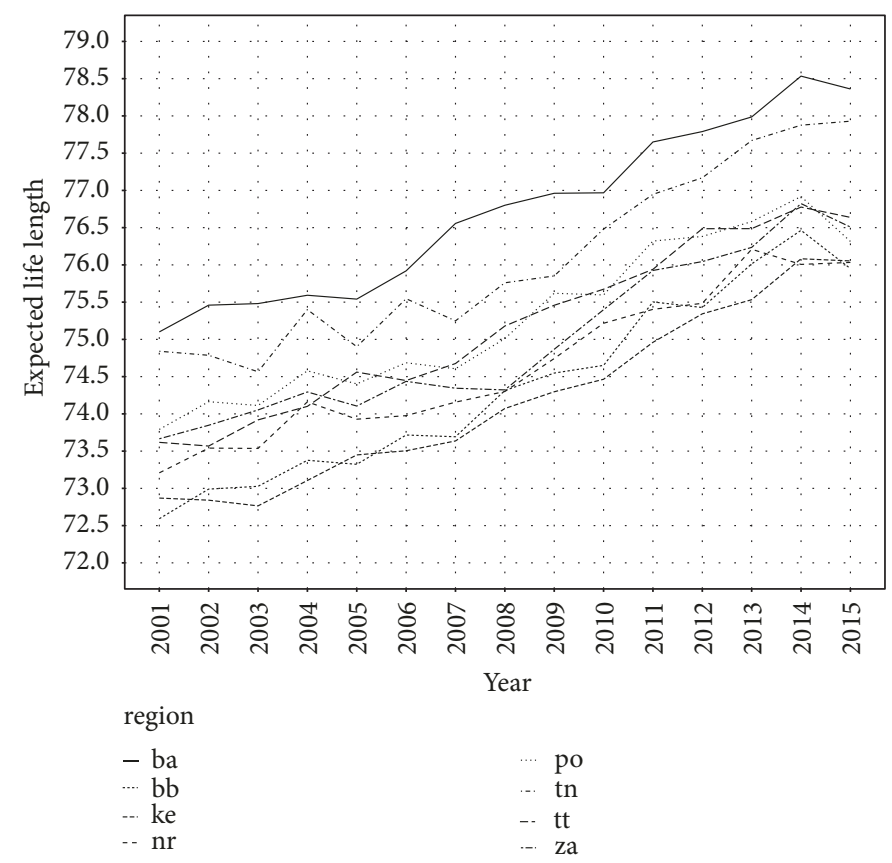

FigurE 1: Expected life length in Slovak regions for all causes of death.

\section{Results and Discussion}

The analysis is divided into two parts. Firstly, we describe the expected life length in Slovak regions for all cause of death as well as when Alzheimer's disease is eliminated. We analyse the potential gain in life expectancy (PGLE) in case of Alzheimer's disease elimination. The second part provides a study of the impact of socioeconomic factors on Alzheimer's disease as the cause of death.

3.1. Expected Life Length. In general, there are significant regional disparities in the Slovak Republic. Western regions belong to the most developed regions with high GDP per capita and very low unemployment rate. On the other hand, eastern part of the Slovak Republic is typically less developed with high unemployment rate. That heterogeneity can be seen in case of expected life length, too. As Figure 1 shows, during all the studied period, Bratislava region (ba) has the highest expected life length. The second highest expected life length has Trenćin region (tn). Regions with the lowest expected life length are Kosice region (ke) and Banská Bystrica region (bb). Both these regions are less developed regions. It is important to emphasise that Prešov region (po), which belongs to the least developed regions, has the third highest expected life length, together with the Trnava region (tt). Life expectancy in Slovak regions at age 0 including all causes of death is presented in Table 1.

Expected life length eliminating Alzheimer's disease in Slovak regions is depicted in Figure 2. Because of the small share of Alzheimer's disease on the causes of deaths, Figures 1 and 2 seem to be the same. But when we look more carefully, we can see several differences between them. Firstly, all values in Figure 2 are quite higher than in Figure 2. The second key aspect is that there are differences among regions, mainly in last years, when the number of deaths caused by Alzheimer's disease increased rapidly. In 2015, in Figure 1, there is Trnava region ( $\mathrm{tt}$ ) closer to the Žilina region ( $\mathrm{za}$ ) than in Figure 2. This means that Trnava region is affected by Alzheimer's disease more than Žilina region. It is because when eliminating Alzheimer's disease, expected life length increases more in case of Trnava region. In other words, Alzheimer's disease decreases real expected life length more in Trnava region as in the Žilina region. Life expectancy at age 0 by complete elimination of Alzheimer's disease for Slovak regions is shown in Table 2.

Potential gain in life expectancy is calculated as difference between the expected life length for all causes of death and the expected life length excluding Alzheimer's disease. Figure 3 shows development of the PGLE in Slovak regions during studied period. Higher PGLE explains that region suffers from Alzheimer's disease more. The most stricken regions are Bratislava region, Trnava region, and Kosice region. On the other hand, the least suffering regions are Banská Bystrica region, Trenčín region, Žilina region, and Nitra region. Prešov region increased in 2015 and is actually region with the second highest PGLE. In all eight Slovak regions PGLE has increased since 2001. The lowest PGLE is in Trenčín region, Žilina region, and Banská Bystrica region. Potential gain in life expectancy at age 0 by complete elimination of Alzheimer's disease for Slovak region is presented in Table 3.

3.2. Socioeconomic Indicators. In this section, we analyse the effect of socioeconomic factors on the potential gain in life expectancy. We study effects of gross domestic product per capita, average wage, unemployment rate, and share of the tertiary educated employees. 
TABLE 1: Life expectancy (in years) at birth (age 0) for Slovak regions.

\begin{tabular}{|c|c|c|c|c|c|c|c|c|}
\hline \multirow{2}{*}{ Year } & \multicolumn{8}{|c|}{ Regions } \\
\hline & ba & $\mathrm{tt}$ & tn & $\mathrm{nr}$ & $\mathrm{za}$ & $\mathrm{bb}$ & po & ke \\
\hline 2001 & 75.100 & 73.618 & 74.840 & 73.208 & 73.665 & 72.592 & 73.791 & 72.870 \\
\hline 2002 & 75.459 & 73.568 & 74.787 & 73.540 & 73.847 & 72.990 & 74.163 & 72.841 \\
\hline 2003 & 75.481 & 73.920 & 74.565 & 73.536 & 74.053 & 73.027 & 74.113 & 72.765 \\
\hline 2004 & 75.592 & 74.101 & 75.400 & 74.161 & 74.294 & 73.377 & 74.578 & 73.106 \\
\hline 2005 & 75.541 & 74.561 & 74.902 & 73.928 & 74.105 & 73.323 & 74.403 & 73.449 \\
\hline 2006 & 75.920 & 74.447 & 75.546 & 73.976 & 74.437 & 73.716 & 74.686 & 73.505 \\
\hline 2007 & 76.557 & 74.676 & 75.249 & 74.157 & 74.344 & 73.693 & 74.606 & 73.637 \\
\hline 2008 & 76.801 & 75.179 & 75.760 & 74.300 & 74.322 & 74.313 & 75.011 & 74.072 \\
\hline 2009 & 76.961 & 75.458 & 75.852 & 74.743 & 74.867 & 74.548 & 75.619 & 74.297 \\
\hline 2010 & 76.968 & 75.673 & 76.481 & 75.216 & 75.398 & 74.651 & 75.596 & 74.465 \\
\hline 2011 & 77.650 & 75.941 & 76.947 & 75.403 & 75.926 & 75.503 & 76.320 & 74.960 \\
\hline 2012 & 77.790 & 76.486 & 77.170 & 75.484 & 76.044 & 75.428 & 76.382 & 75.343 \\
\hline 2013 & 77.986 & 76.487 & 77.670 & 76.210 & 76.235 & 76.014 & 76.582 & 75.533 \\
\hline 2014 & 78.534 & 76.776 & 77.876 & 76.007 & 76.823 & 76.464 & 76.918 & 76.082 \\
\hline 2015 & 78.362 & 76.638 & 77.929 & 76.033 & 76.508 & 75.950 & 76.315 & 76.053 \\
\hline
\end{tabular}

Note: ba: Bratislava region, tt: Trnava region, tn: Trenčín region, nr: Nitra region, bb: Banská Bystrica region, po: Prešov region, and ke: Košice region.
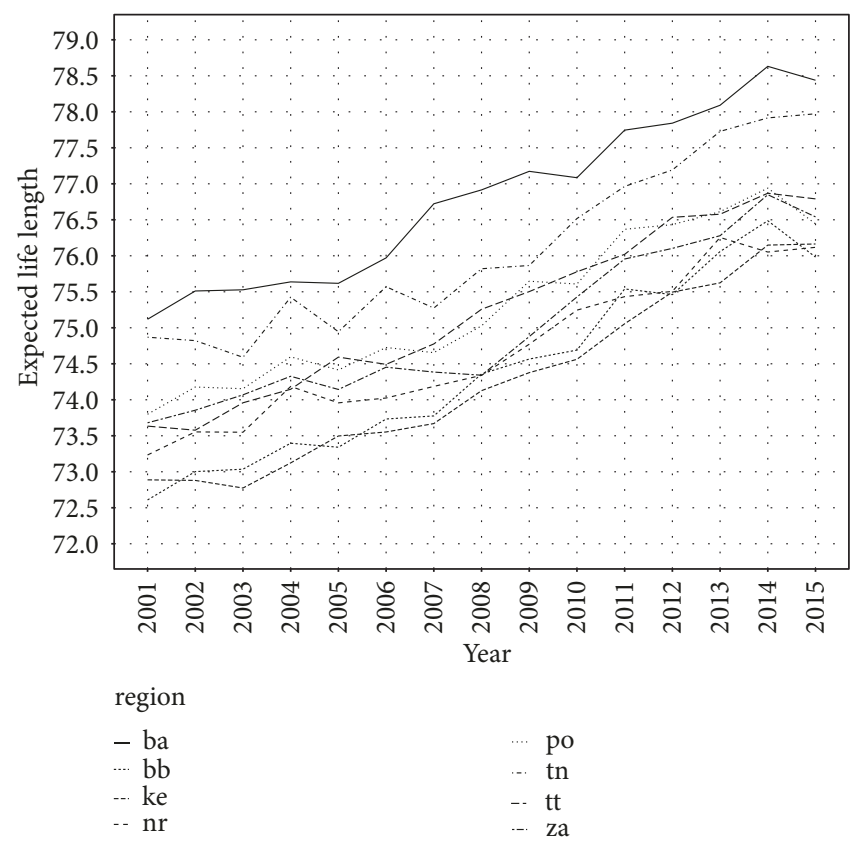

Figure 2: Expected life length in Slovak regions eliminating Alzheimer's disease.

As mentioned above, Slovak Republic is very heterogeneous country. There are significant regional disparities, which are nicely presented by regional GDP per capita, depicted in Figure 4. Bratislava region has the highest GDP per capita in each year. Negative aspect is that the difference between Bratislava region and other regions is still growing. In 2001, GDP per capita in Bratislava region was 15,000 EUR and in other regions was only 5,000 EUR. In 2015, it was 35,000 in Bratislava region and about 10,000 in other regions.

The same situation is in average wage. The highest average wage is in Bratislava region. During studied period, it has increased from 600 EUR in 2001 to 1,100 EUR in 2015. The lowest average wage is in Prešov region in each year. It has grown from less than 400 EUR in 2001 to almost 800 EUR in 2015. The divergence between Bratislava region and group of other regions is significant. Average wage is shown in Figure 5, where we can see that average wage in Bratislava region reacted more sensitively on economic crisis in 2009 than wage in other regions.

Unemployment rate was in Bratislava region the lowest in each year, which is shown in Figure 6. On the second place, there is Trenčín region and the third is Trnava region; all 
TABLE 2: Life expectancy (in years) at birth (age 0) by complete elimination of Alzheimer's disease for Slovak regions.

\begin{tabular}{lcccccccc}
\hline \multirow{2}{*}{ Year } & ba & tt & tn & nr & za & bb & po \\
\hline 2001 & 75.118 & 73.634 & 74.869 & 73.233 & 73.680 & 72.608 & 73.799 \\
\hline 2002 & 75.511 & 73.578 & 74.822 & 73.554 & 73.855 & 73.002 & 74.177 \\
\hline 2003 & 75.527 & 73.958 & 74.590 & 73.549 & 74.069 & 73.036 & 74.154 & 72.887 \\
\hline 2004 & 75.638 & 74.146 & 75.425 & 74.185 & 74.326 & 73.397 & 74.597 \\
\hline 2005 & 75.618 & 74.593 & 74.945 & 73.957 & 74.143 & 73.341 & 74.414 & 73.123 \\
\hline 2006 & 75.971 & 74.492 & 75.570 & 74.025 & 74.452 & 73.733 & 74.726 & 73.497 \\
\hline 2007 & 76.723 & 74.776 & 75.274 & 74.186 & 74.385 & 73.776 & 74.655 \\
\hline 2008 & 76.915 & 75.257 & 75.820 & 74.339 & 74.341 & 74.359 & 75.027 \\
\hline 2009 & 77.173 & 75.503 & 75.865 & 74.772 & 74.878 & 74.566 & 75.647 \\
\hline 2010 & 77.085 & 75.778 & 76.518 & 75.245 & 75.429 & 74.690 & 75.608 \\
\hline 2011 & 77.746 & 76.020 & 76.963 & 75.432 & 75.955 & 75.539 & 76.127 \\
\hline 2012 & 77.842 & 76.535 & 77.193 & 75.506 & 76.103 & 75.461 & 76.368 \\
\hline 2013 & 78.091 & 76.578 & 77.728 & 76.254 & 76.279 & 76.059 & 733 \\
\hline 2014 & 78.632 & 76.869 & 77.915 & 76.052 & 76.849 & 76.487 & 76.613 \\
\hline 2015 & 78.439 & 76.791 & 77.972 & 76.118 & 76.541 & 75.982 & 76.940 \\
\hline
\end{tabular}

Note: ba: Bratislava region, tt: Trnava region, tn: Trenčín region, nr: Nitra region, bb: Banská Bystrica region, po: Prešov region, and ke: Košice region.

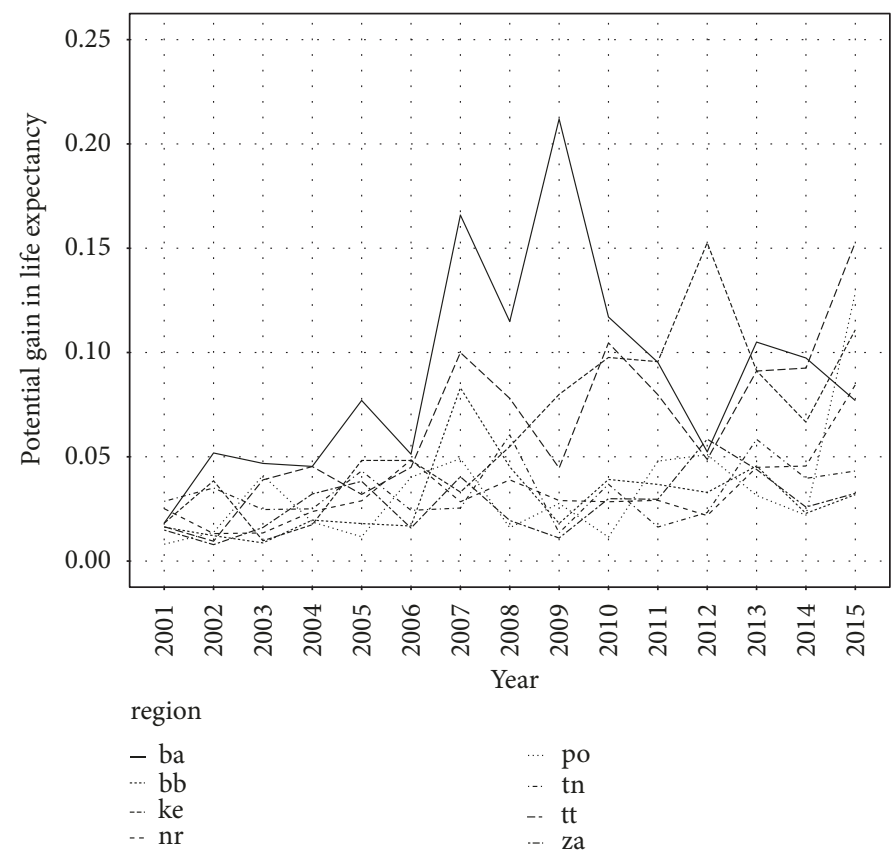

FIgURE 3: Potential gain in life expectancy by Alzheimer's disease elimination in Slovak regions.

regions are located in the western part of the Slovak Republic. Among regions with the highest unemployment rate there are Prešov region, Banská Bystrica region, and Košice region, which are situated in the eastern part of the country and southern part in case of Banská Bystrica region. Here, we can see two positive aspects. First is that unemployment rate has declined in all regions and the second is that differences between the best and the worst region are decreasing.

The last analysed socioeconomic factor is education, in our case the percentage of tertiary educated employees. As well as in the previous indicators, Bratislava region with the highest share of tertiary educated employees differs markedly from other regions. Percentage of tertiary educated employees has increased in all regions. The lowest value has Trnava region. Development of tertiary educated employees in Slovak regions is depicted in Figure 7.

3.3. Socioeconomic Effects on the PGLE. We applied panel data analysis to measure the impact of the selected socioeconomic indicators on the potential gain in life expectancy. 
TABle 3: Potential gains in life expectancy (in years) at birth (age 0) by complete elimination of Alzheimer's disease for Slovak regions.

\begin{tabular}{lccccccccc}
\hline Year & ba & tt & tn & nr & za & bb & po \\
\hline 2001 & 0.018 & 0.016 & 0.029 & 0.025 & 0.015 & 0.016 & 0.008 \\
\hline 2002 & 0.050 & 0.010 & 0.035 & 0.013 & 0.008 & 0.012 & 0.014 \\
\hline 2003 & 0.047 & 0.039 & 0.025 & 0.013 & 0.016 & 0.008 & 0.041 & 0.038 \\
\hline 2004 & 0.045 & 0.045 & 0.025 & 0.024 & 0.032 & 0.020 & 0.019 \\
\hline 2005 & 0.077 & 0.032 & 0.043 & 0.029 & 0.038 & 0.018 & 0.012 & 0.010 \\
\hline 2006 & 0.051 & 0.045 & 0.024 & 0.049 & 0.016 & 0.017 & 0.040 & 0.048 \\
\hline 2007 & 0.166 & 0.100 & 0.025 & 0.028 & 0.040 & 0.083 & 0.049 \\
\hline 2008 & 0.115 & 0.078 & 0.060 & 0.039 & 0.019 & 0.045 & 0.016 \\
\hline 2009 & 0.212 & 0.045 & 0.014 & 0.029 & 0.011 & 0.018 & 0.033 \\
\hline 2010 & 0.117 & 0.105 & 0.037 & 0.028 & 0.030 & 0.039 & 0.055 \\
\hline 2011 & 0.095 & 0.080 & 0.016 & 0.029 & 0.030 & 0.037 & 0.011 \\
\hline 2012 & 0.052 & 0.049 & 0.023 & 0.022 & 0.058 & 0.033 & 0.048 \\
\hline 2013 & 0.105 & 0.091 & 0.058 & 0.045 & 0.044 & 0.046 & 0.051 & 0.031 \\
\hline 2014 & 0.097 & 0.093 & 0.040 & 0.046 & 0.026 & 0.023 & 0.096 \\
\hline 2015 & 0.077 & 0.153 & 0.043 & 0.085 & 0.032 & 0.032 & 0.153 \\
\hline
\end{tabular}

Note: ba: Bratislava region, tt: Trnava region, tn: Trenčín region, nr: Nitra region, bb: Banská Bystrica region, po: Prešov region, and ke: Košice region.
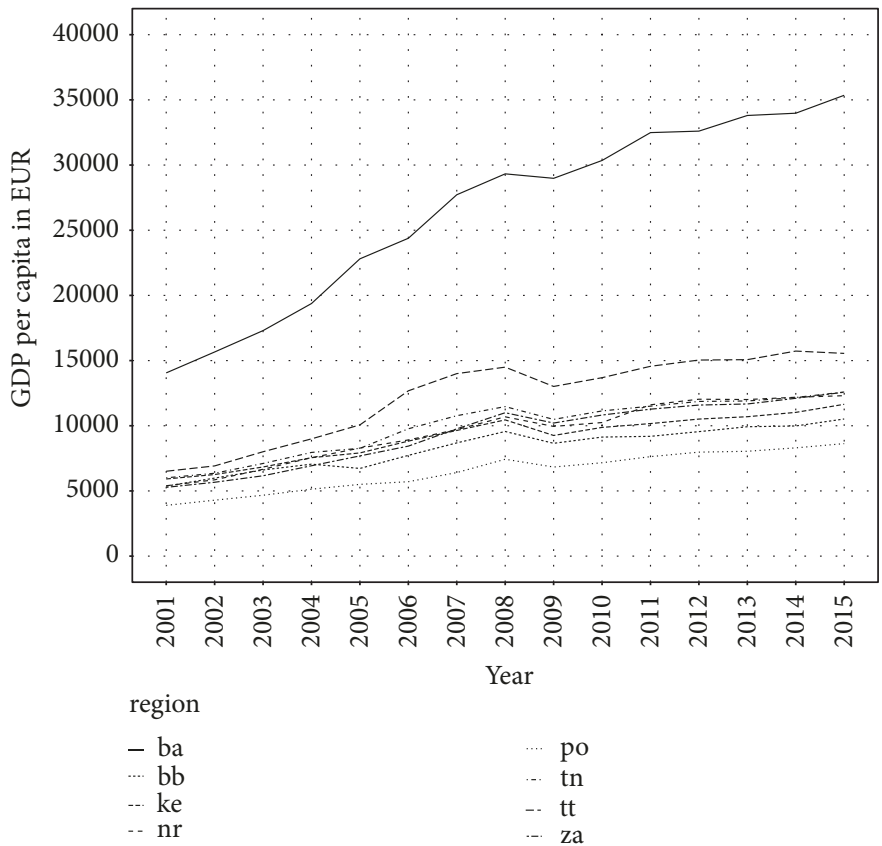

FIGURE 4: GDP per capita in Slovak regions.

We estimated three linear panel models with PGLE as dependent variable and four independent variables: GDP, wage, unemployment, and education. First model is fixed effects model, second is random effects model, and the third is pooling model (3). According to poolability test, the most appropriate model is pooling model, which has also the highest R-Squared, too. This means that region does not affect the level of expected life length reduction caused by Alzheimer's disease. Estimates of all three models are presented in Table 4. We used logarithmic modification to ensure stationarity of variables.
Estimated regression coefficients from pooling model (3) show that statistically significant variables are GDP, wage and education. Estimated coefficient of variable GDP is positive, which means that the increase in change of the GDP in region causes the increase in change of the potential gain in life expectancy. This can be interpreted that number of deaths caused by Alzheimer's disease grows with increase in change of the GDP. The same situation is in case of the wage. Regression coefficient of the variable wage is positive; therefore the increase in change of the wage in the region causes increase in the change of the potential gain in life 


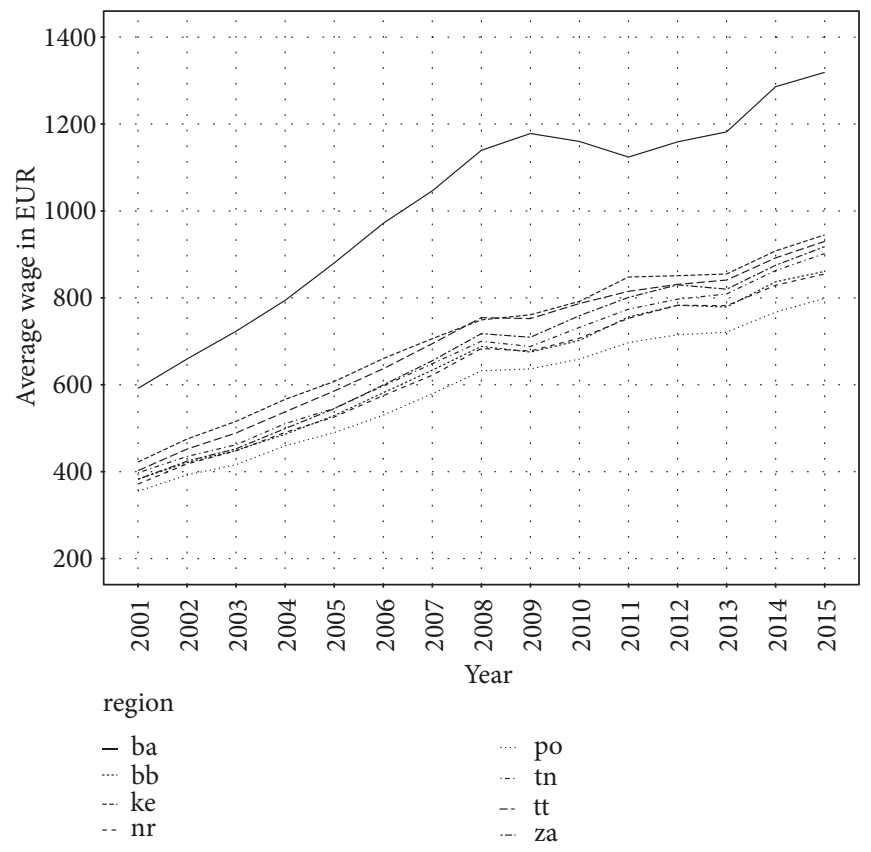

FIGURE 5: Average wage in Slovak regions.

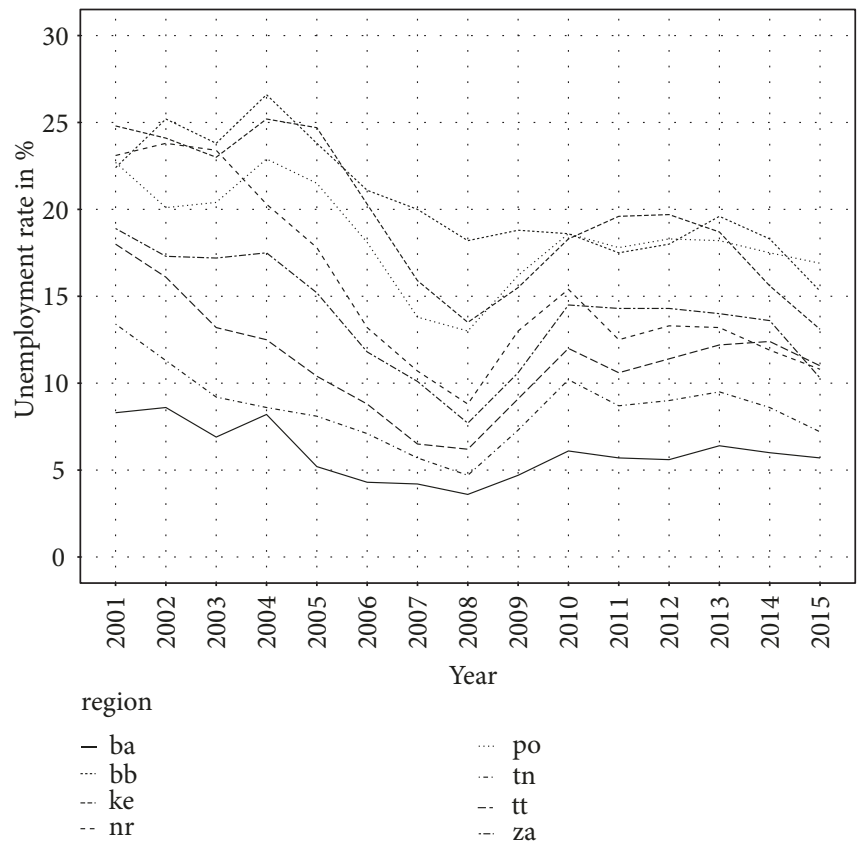

FIGURE 6: Unemployment rate in Slovak regions.

expectancy, which means more deaths caused by Alzheimer's disease. On the other side, estimated regression coefficient of the variable education has negative sign, so if we increase the change of the percentage of the tertiary educated employees, it leads to declination of the change of the potential gain in life expectancy, which means less deaths caused by Alzheimer's disease.

\section{Discussion}

Similar to other findings in literature, our study confirms that the number of deaths caused by Alzheimer's disease has increased rapidly. Due to the economic development and the improvement of social conditions over the last decades, life expectancy has grown, which might explain the increasing 


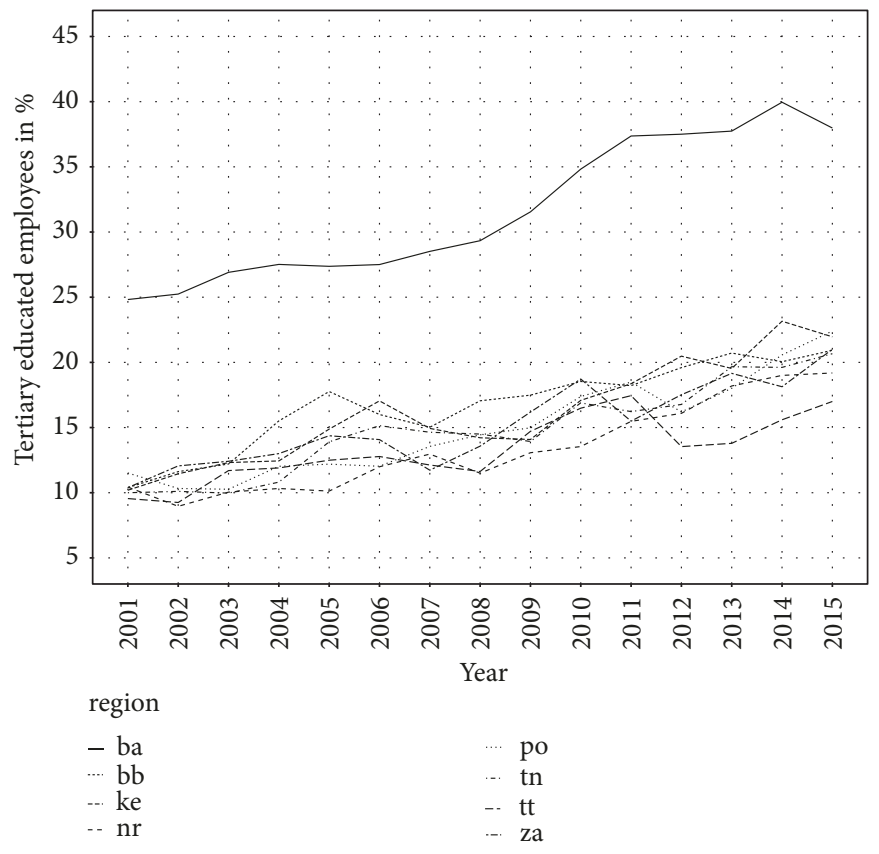

Figure 7: Percentage of tertiary educated employees in Slovak regions.

TABLE 4: Estimated coefficients of linear panel models.

\begin{tabular}{|c|c|c|c|c|c|}
\hline \multirow{2}{*}{\multicolumn{2}{|c|}{$\begin{array}{c}\text { Fixed effects model } \\
(1) \\
\text { Estimate } \\
\end{array}$}} & \multicolumn{2}{|c|}{$\begin{array}{c}\text { Random effects model } \\
(2)\end{array}$} & \multicolumn{2}{|c|}{$\begin{array}{l}\text { Pooling model } \\
\text { (3) }\end{array}$} \\
\hline & & Est & & \multicolumn{2}{|c|}{ Estimate } \\
\hline Intercept & - & -16.10361 & $* * *$ & -19.69592 & $* * *$ \\
\hline $\log (\mathrm{GDP})$ & 0.00666 & 0.36724 & & 0.61835 & $*$ \\
\hline Log(WAGE) & 1.41820 & 1.38012 & $* * *$ & 1.45152 & $* * *$ \\
\hline Log(UNEM) & -0.19705 & -0.01797 & & 0.14204 & \\
\hline $\log ($ EDU $)$ & -0.00456 & -0.25301 & & -0.47277 & $*$ \\
\hline R-Squared & 0.35220 & 0.42397 & & 0.49238 & \\
\hline
\end{tabular}

Note: $* * *, * * *$ denote significance levels on 1,5 , and 10 percent, respectively. GDP represents gross domestic product per capita, WAGE is average wage, UNEM denotes unemployment rate, and EDU is percentage of tertiary educated employees. According to the poolability test for individual cross-sectional effects using fixed effects model, all coefficients, excluding intercepts, are equal for individual effects $(\mathrm{F}=1.432)$ as well as for time effects $(\mathrm{F}=0.770)$. $\mathrm{F}$ test confirmed an existence of individual effects $(\mathrm{F}=2.916 * * *)$ and absence of time effects $(\mathrm{F}=1,113)$. There is not present cross-sectional dependence according to the Pesaran CD test $(\mathrm{Z}=-0.351)$. Breusch-Godfrey test for serial correlation in panel models did not confirm an existence of the serial correlation (Chisquared=21.769). Hausman test prefers application of the (Chi-squared=3.056) fixed effects model (1).

public health issue. In 2013, Abubakar et al. [22] found that Alzheimer's disease was one of the top 50 global causes of years of life lost, which was caused by the increase in the last years. According to Mathers and Loncar [23], Alzheimer's disease will be the seventh highest cause of death in highincome countries in the year 2030.

The main aim of the paper is the analysis of the relationship between Alzheimer's disease and socioeconomic factors as GDP, wage, and education. This is supported by previous studies which showed that these factors of socioeconomic status influence prevalence of the disease. Many large population-based studies have looked at the impact of socioeconomic status on the prevalence of dementia [13, $14,24,25]$. The majority of these studies confirmed a clear relationship between the prevalence of dementia and low socioeconomic status. Fischer et al. [26] analysed patients with Alzheimer's disease and found out a strong association between age, individual annual income range, education, medical comorbidity, and a diagnosis of dementia, with increased age and medical comorbidity being the strongest predictors. The low socioeconomic status is often associated with insufficient access to the health care but this is not the case of Slovakia, where health care is accessible to all population. This might be a reason that GDP per capita and average wage increase Alzheimer's disease burden. Another reason of that fact can be that labour positions with high qualification and labour positions with low qualification do not differ in wage enough, especially in automotive industry. Goldbourt, Schnaider-Beeri, and Davidson [27] discovered from three- to sixfold increase in the prevalence of dementia 
among patients with low socioeconomic status versus those with high socioeconomic status. Lang et al. [28] found that living in an economically deprived locality results in a high prevalence of dementia, independent of other factors of socioeconomic status, such as annual income and education.

The relationship between education and Alzheimer's disease or dementia has been widely examined over the past decade [29, 30]. In our study, higher education level was linked with lower mortality rates. There are several studies with opposite findings. An inverse association between educational level and the risk of Alzheimer's disease or dementia has been reported in cross-sectional [31-34] and case-control studies [10, 35]. Several incidence studies [36] and pooled incidence data from Europe [37] also demonstrate an inverse association between education and Alzheimer's disease or dementia. In contrast, other incidence studies [38, 39] as well as autopsy-verified studies [40, 41] have failed to find any evidence for this reverse relationship. The data might have been influenced by neglection of the effects of potential confounders, such as cognitive functioning prior to dementia, vascular diseases, and socioeconomic status.

Katzman [29] proposed that education could postpone the clinical expression of dementia symptoms by increasing the neocortical synaptic density (the "brain reserve" hypothesis). Letenneur et al. [42] suggested that educational and occupational attainment provided a reserve against dementia, in that persons with higher educational and occupational attainment could cope with advanced pathologic changes of the disease more effectively by maintaining function longer (the "cognitive reserve" hypothesis). In addition, we assume that the observed inverse association may reflect an earlier detection of demented subjects with a low level of education irrespective of the underlying pathologic progress. Majority of brain reserve studies have used education as a brain-reserve measure [40-42]. In another study, Qiu et al. [4] suggest that a low level of education is associated with an increased risk of developing clinical Alzheimer's disease or dementia, particularly in women and in youngerold age. In addition, a low level of education was related to increased mortality of all causes, but not to mortality of subjects with Alzheimer's disease or dementia in the general population. A low educational level was significantly related to all-cause mortality, but not to the mortality of subjects with Alzheimer's disease or dementia. Alternatively, the observed association between educational level and incidence of Alzheimer's disease or dementia may partly reflect detection bias, by which subjects with a low level of education tend to be clinically diagnosed at an earlier point in time.

\section{Conclusion}

Aim of the paper was to analyse the impact of socioeconomic factors on the life expectancy in Slovak regions by complete elimination of Alzheimer's disease. It is calculated as difference between life expectancy eliminating Alzheimer's disease and life expectancy for all causes of deaths. We used potential gain in life expectancy method to quantify influence of Alzheimer's disease on the life expectancy. This method showed that there are significant differences among Slovak regions.

Potential gain in life expectancy was subsequently used as dependent variable in panel model analysis in order to identify the impact of socioeconomic factors on the life expectancy. We analysed effects of the gross domestic product per capita, average monthly wage, unemployment rate, and education level. According to our results, unemployment rate does not affect the mortality caused by Alzheimer's disease. On the other hand, gross domestic product, average wage, and education influence statistically significant mortality caused by Alzheimer's disease. Education has indirect effect on the mortality caused by Alzheimer's disease. This is the same result as results from previous studies. Increase in wage and gross domestic product leads to the increase in mortality caused by Alzheimer's disease. This is in opposite of other studies, because, according to these studies, higher level of socioeconomic status decreases prevalence to Alzheimer's disease.

\section{Data Availability}

The data comes from the database of the National Health Information Centre of the Slovak Republic, Statistical Office of the Slovak Republic, and Eurostat Directorate-General of the European Commission in Luxembourg.

\section{Conflicts of Interest}

The authors declare that they have no conflicts of interest.

\section{Acknowledgments}

This paper was created within the project supported by the Scientific Grant Agency of the Ministry of Education, Science, Research and Sport of the Slovak Republic: Project VEGA No. 1/0846/18: "Evaluation of the efficiency of public procurement of selected commodities in healthcare facilities in the Slovak Republic". Our thanks go out to the National Health Information Centre of the Slovak Republic for providing access to the central mortality database for the explored period as well as the other studied data along with the Statistical Office of the Slovak Republic. Our acknowledgments also belong to the Ministry of Health of the Slovak Republic for its cooperation in creation of the new conceptions and methodologies and for its support of our research activities.

\section{References}

[1] M. Prince, R. Bryce, E. Albanese, A. Wimo, W. Ribeiro, and C. P. Ferri, "The global prevalence of dementia: a systematic review and metaanalysis," Alzheimer's \& Dementia, vol. 9, no. 1, pp. 6375, 2013.

[2] Alzheimer Europe, Discussion paper on ethical issues linked to the changing definitions/use of terms related to Alzheimer's disease, Alzheimer Europe, Luxembourg, 2016.

[3] M. Prince, A. Comas-Herrera, M. Knapp et al., "World Alzheimer report 2016: improving healthcare for people living 
with dementia: coverage, quality and costs now and in the future," 2016.

[4] C. Qiu, L. Bäckman, B. Winblad, H. Aguero-Torres, and L. Fratiglioni, "The influence of education on clinically diagnosed dementia incidence and mortality data from the Kungsholmen Project," JAMA Neurology, vol. 58, no. 12, pp. 2034-2039, 2001.

[5] D. M. Castro, C. Dillon, G. Machnicki, and R. F. Allegri, "The economic cost of Alzheimer's disease: Family or public health burden?" Dementia \& Neuropsychologia, vol. 4, no. 4, pp. 262267, 2010.

[6] C. Reed, M. Happich, J. M. Argimon et al., "What Drives Country Differences in Cost of Alzheimer's Disease? An Explanation from Resource Use in the GERAS Study," Journal of Alzheimer's Disease, vol. 57, no. 3, pp. 797-812, 2017.

[7] B. Winblad, P. Amouyel, S. Andrieu et al., "Defeating Alzheimer's disease and other dementias: A priority for European science and society," The Lancet Neurology, vol. 15, no. 5, pp. 455-532, 2016.

[8] N. Merkuri, "European Dementia Monitor 2017-Comparing and benchmarking national dementia strategies and policies," 2017.

[9] V. Nicolia, M. Lucarelli, and A. Fuso, "Environment, epigenetics and neurodegeneration: focus on nutrition in Alzheimer's disease," Experimental Gerontology, vol. 68, pp. 8-12, 2015.

[10] V. M. Moceri, W. A. Kukull, I. Emanual et al., "Using Census Data and Birth Certificates to Reconstruct the Early-Life Socioeconomic Environment and the Relation to the Development of Alzheimer's Disease," Epidemiology, vol. 12, no. 4, pp. 383-389, 2001.

[11] R. N. Kalaria, G. E. Maestre, R. Arizaga et al., "Alzheimer's disease and vascular dementia in developing countries: prevalence, management, and risk factors," The Lancet Neurology, vol. 7, no. 9, pp. 812-826, 2008.

[12] A. Ertekin, R. Demir, G. Özdemir, L. Özel, E. Özyıldırım, and H. Ulvi, "An investigation of the risk factors and prevalence of alzheimer's disease in the eastern region of Turkey : A population based door-to-door survey," European Journal of General Medicine, vol. 12, no. 2, pp. 144-151, 2015.

[13] A. Karp, I. Kåreholt, C. Qiu, T. Bellander, B. Winblad, and L. Fratiglioni, "Relation of Education and Occupation-based Socioeconomic Status to Incident Alzheimer's Disease," American Journal of Epidemiology, vol. 159, no. 2, pp. 175-183, 2004.

[14] D. A. Evans, L. E. Hebert, L. A. Beckett et al., "Education and other measures of socioeconomic status and risk of incident Alzheimer disease in a defined population of older persons," JAMA Neurology, vol. 54, no. 11, pp. 1399-1405, 1997.

[15] G. D. Wang, D. J. Lai, K. D. Burau, and X. L. Du, "Potential gains in life expectancy from reducing heart disease, cancer, Alzheimer's disease, kidney disease or HIV/AIDS as major causes of death in the USA," Public Health, vol. 127, no. 4, pp. 348-356, 2013.

[16] J. H. Jones, "DemogR: A package for the construction and analysis of age-structured demographic models in R," Journal of Statistical Software, vol. 22, no. 10, pp. 1-28, 2007.

[17] T. N. Greville, "Short Methods of Constructing Abridged Life Tables," in Mathematical Demography, vol. 6 of Biomathematics, pp. 53-60, Springer, Berlin, Heidelberg, Germany, 1977.

[18] E. Arias, M. Heron, and B. Tejada-Vera, "United States life tables eliminating certain causes of death, 1999-2001," National Vital Statistics Reports, vol. 61, no. 9, 2013.
[19] S. P. Tsai, E. S. Lee, and R. J. Hardy, "The effect of a reduction in leading causes of death: potential gains in life expectancy," American Journal of Public Health, vol. 68, no. 10, pp. 966-971, 1978.

[20] Y. Croissant and G. Millo, "Panel data econometrics in R: The plm package," Journal of Statistical Software, vol. 27, no. 2, pp. $1-43,2008$.

[21] Y. Honda, "Testing the error components model with nonnormal disturbances," The Review of Economic Studies, vol. 52, no. 4, pp. 681-690, 1985.

[22] I. I. Abubakar, T. Tillmann, and A. Banerjee, "Global, regional, and national age-sex specific all-cause and cause-specific mortality for 240 causes of death, 1990-2013: a systematic analysis for the Global Burden of Disease Study 2013," Lancet, vol. 385, no. 9963, pp. 117-171, 2015.

[23] C. D. Mathers and D. Loncar, "Projections of global mortality and burden of disease from 2002 to 2030," PLoS Medicine, vol. 3, no. 11, article e442, 2006.

[24] A. Koster, B. W. J. H. Penninx, H. Bosma et al., "Socioeconomic differences in cognitive decline and the role of biomedical factors," Annals of Epidemiology, vol. 15, no. 8, pp. 564-571, 2005.

[25] M. Scazufca, P. R. Menezes, H. P. Vallada et al., "High prevalence of dementia among older adults from poor socioeconomic backgrounds in São Paulo, Brazil," International Psychogeriatrics, vol. 20, no. 2, pp. 394-405, 2008.

[26] C. Fischer, E. Yeung, T. Hansen et al., "Impact of socioeconomic status on the prevalence of dementia in an inner city memory disorders clinic," International Psychogeriatrics, vol. 21, no. 6, pp. 1096-1104, 2009.

[27] U. Goldbourt, M. Schnaider-Beeri, and M. Davidson, "Socioeconomic status in relationship to death of vascular disease and late-life dementia," Journal of the Neurological Sciences, vol. 257, no. 1-2, pp. 177-181, 2007.

[28] I. A. Lang, D. J. Llewellyn, K. M. Langa, R. B. Wallace, F. A. Huppert, and D. Melzer, "Neighborhood deprivation, individual socioeconomic status, and cognitive function in older people: Analyses from the english longitudinal study of ageing," Journal of the American Geriatrics Society, vol. 56, no. 2, pp. 191198, 2008.

[29] R. Katzman, "Education and the prevalence of dementia and Alzheimer's disease," Neurology, vol. 43, no. 1, pp. 13-20, 1993.

[30] C. J. Gilleard, "Education and Alzheimer's disease: A review of recent international epidemiological studies," Aging \& Mental Health, vol. 1, no. 1, pp. 33-46, 1997.

[31] L. R. Hill, M. R. Klauber, D. P. Salmon et al., "Functional status, education, and the diagnosis of dementia in the Shanghai survey," Neurology, vol. 43, no. 1, pp. 138-145, 1993.

[32] A. Ott, M. M. B. Breteler, F. van Harskamp et al., "Prevalence of Alzheimer's disease and vascular dementia: association with education. The Rotterdam study," British Medical Journal, vol. 310, no. 6985, pp. 970-973, 1995.

[33] M. Prencipe, A. R. Casini, C. Ferretti, M. T. Lattanzio, M. Fiorelli, and F. Culasso, "Prevalence of dementia in an elderly rural population: Effects of age, sex, and education," Journal of Neurology, Neurosurgery \& Psychiatry, vol. 60, no. 6, pp. 628633, 1996.

[34] B. Schmand, J. Smit, J. Lindeboom et al., "Low education is a genuine risk factor for accelerated memory decline and dementia," Journal of Clinical Epidemiology, vol. 50, no. 9, pp. 1025-1033, 1997. 
[35] I. Mc Dowell, G. Hill, J. Lindsay et al., "The canadian study of health and aging: Risk factors for alzheimer's disease in Canada," Neurology, vol. 44, no. 11, pp. 2073-2080, 1994.

[36] Y. Stern, B. Gurland, T. K. Tatemichi, M. X. Tang, D. Wilder, and R. Mayeux, "Influence of education and occupation on the incidence of Alzheimer's disease," The Journal of the American Medical Association, vol. 271, no. 13, pp. 1004-1010, 1994.

[37] L. Letenneur, L. J. Launer, K. Andersen et al., "Education and the risk for Alzheimer's disease: sex makes a difference EURODEM pooled analyses," American Journal of Epidemiology, vol. 151, no. 11, pp. 1064-1071, 2000.

[38] J. L. Cobb, P. A. Wolf, R. Au, R. White, and R. B. D'agostino, “The effect of education on the incidence of dementia and alzheimer's disease in the framingham study," Neurology, vol. 45, no. 9, pp. 1707-1712, 1995.

[39] K. S. Hall, S. Gao, F. W. Unverzagt, and H. C. Hendrie, "Low education and childhood rural residence: Risk for Alzheimer's disease in African Americans," Neurology, vol. 54, no. 1, pp. 9599, 2000.

[40] J. V. Bowler, D. G. Munoz, H. Merskey, and V. Hachinski, "Factors affecting the age of onset and rate of progression of Alzheimer's disease," Journal of Neurology, Neurosurgery \& Psychiatry, vol. 65, no. 2, pp. 184-190, 1998.

[41] T. Del Ser, V. Hachinski, H. Merskey, and D. G. Munoz, "An autopsy-verified study of the effect of education on degenerative dementia," Brain, vol. 122, no. 12, pp. 2309-2319, 1999.

[42] L. Letenneur, V. Gilleron, D. Commenges, C. Helmer, J. M. Orgogozo, and J. F. Dartigues, "Are sex and educational level independent predictors of dementia and Alzheimer's disease? Incidence data from the PAQUID project," Journal of Neurology, Neurosurgery \& Psychiatry, vol. 66, no. 2, pp. 177-183, 1999. 


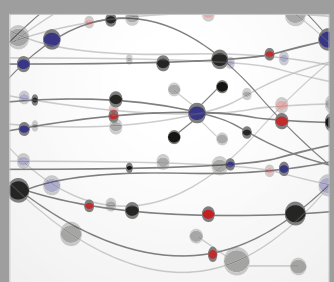

The Scientific World Journal
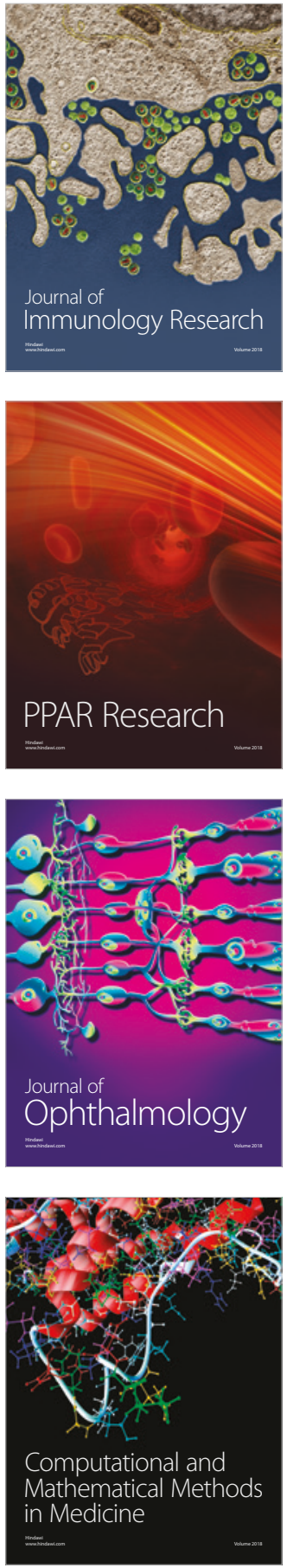

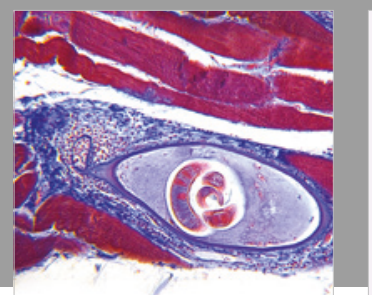

Gastroenterology Research and Practice

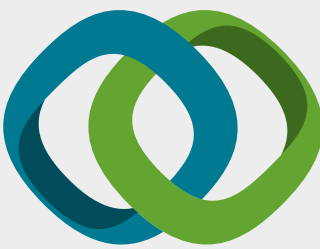

\section{Hindawi}

Submit your manuscripts at

www.hindawi.com
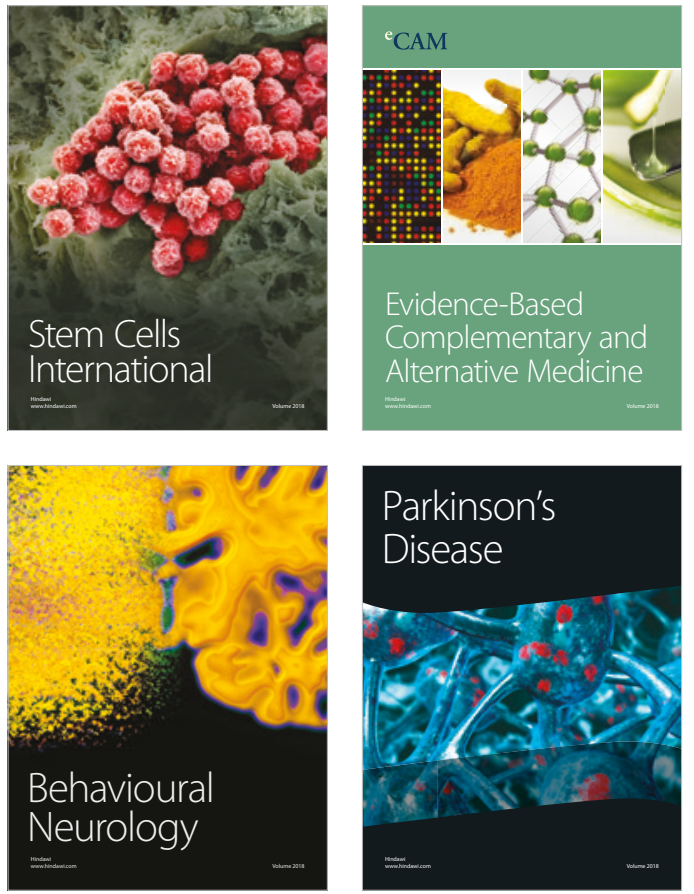

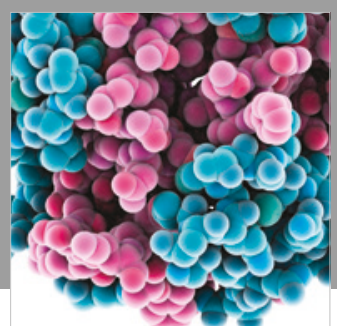

ournal of

Diabetes Research

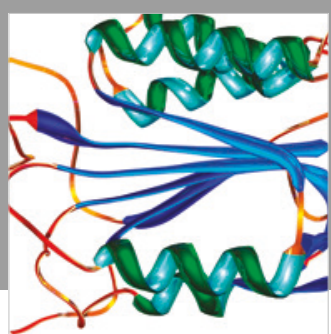

Disease Markers
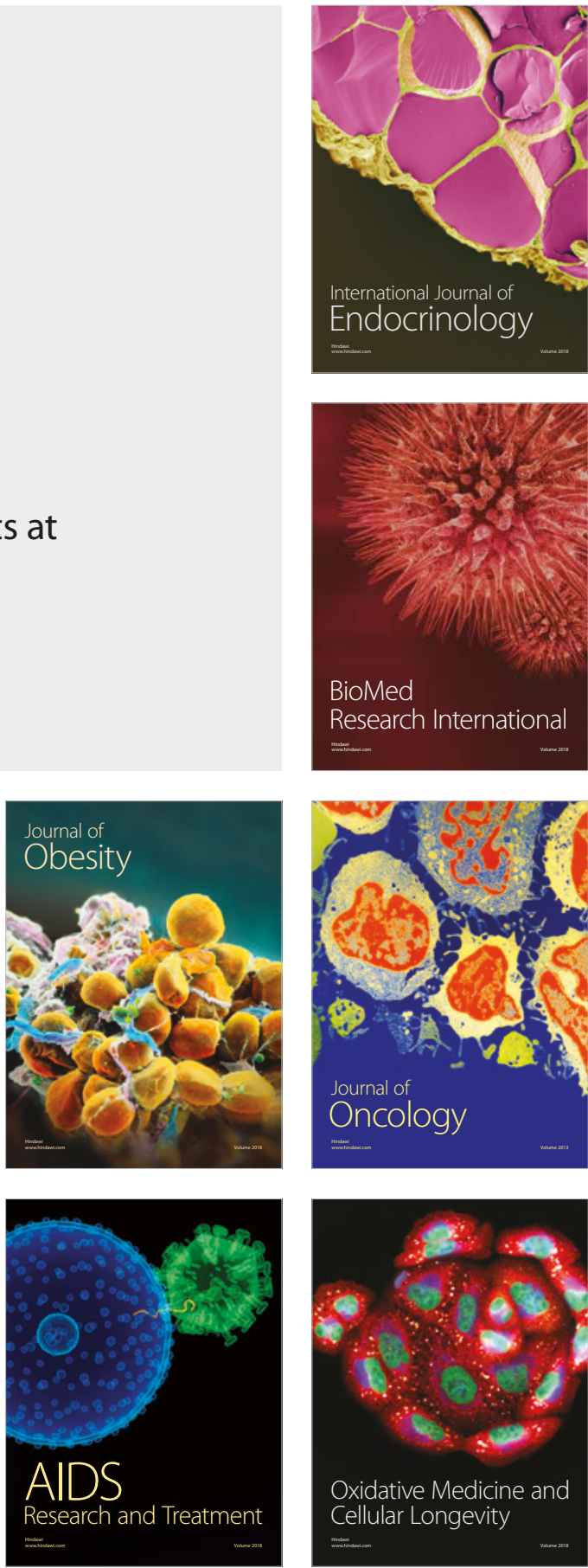